\title{
REINJECTION INTO GEOTHERMAL RESERVOIRS
}

\section{GUDMUNDUR S. BODVARSSON \& VALGARDUR STEFANSSON ${ }^{+}$}

*Earth Sciences Division, Lawrence Berkeley Laboratory

University of California, Berkeley, California 94720 USA

LBL- -23949

+Braedraborgarstigur 23, Reykjavik, Iceland

DE88 003196

\section{INTRODUCTION}

Reinjection of geothermal wastewater is practised at many geothermal fields as a means of disposal and for reservoir pressure support. Surface disposal of the wastewater is prohibited in most fields due to environmental reasons. Reinjection of the wastewater for pressure support is also very important at various fields, especially those located in agricultural regions such as the Imperial Valley, where no significant subsidence can be tolerated. In most of the fields in the U.S. currently under development, including Heber, East Mesa, Salton Sea, Dixie Valley, and Roosevelt Hot Springs, 70 to $100 \%$ of the produced fluids are being reinjected.

The design and implementation of an injection scheme for a given field is very important and far from being an easy task. Various problems have been experienced during injection operations, including injectivity decreases, scaling problems, and temperature declines in nearby producers. Thus, in designing the appropriate reinjection scheme for a field, the chemical characteristics of the produced fluids play an important role. Also the geological structure of the site must be understood in order to avoid locating the injection wells where "fast paths" such as faults and fractures will short-circuit the injected water to producers. the benefits of injection on the overall reservoir performance should be substantial. In addition to the pressure support, injection will help extract the heat from the tight matrix blocks and greatly increase the energy recovery from the system.

In this paper, various aspects of reinjection are discussed, both in terms of theoretical studies that have been conducted as well as specific field examples. The discussion focuses on the major effects of reinjection, including pressure maintenance, and chemical and thermal effects.

\section{PRESSURE MAINTENANCE}

Theoretical Studies

Various theoretical studies have been carried out to investigate the effects of reinjection on pressure maintenance in geothermal reservoirs (e.g., Lippmann et al., 1977; Schroeder et al., 1980; Tsang et al., 1984; Bodvarsson et al., 1985; Calore et al., 1986). These studies have shown that injection has rather different effects on the reservoir response depending on the initial thermodynamic state of the reservoir. In the case of a liquid water reservoir the pressure effects of reinjection can readily be evaluated using conventional analytical and numerical techniques, taking into

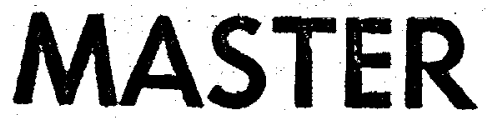




\section{DISCLAIMER}

This report was prepared as an account of work sponsored by an agency of the United States Government. Neither the United States Government nor any agency Thereof, nor any of their employees, makes any warranty, express or implied, or assumes any legal liability or responsibility for the accuracy, completeness, or usefulness of any information, apparatus, product, or process disclosed, or represents that its use would not infringe privately owned rights. Reference herein to any specific commercial product, process, or service by trade name, trademark, manufacturer, or otherwise does not necessarily constitute or imply its endorsement, recommendation, or favoring by the United States Government or any agency thereof. The views and opinions of authors expressed herein do not necessarily state or reflect those of the United States Government or any agency thereof. 


\section{DISCLAIMER}

Portions of this document may be illegible in electronic image products. Images are produced from the best available original document. 
account the specific reservoir characteristics and pressure and temperature dependent fluid (and perhaps rock matrix) properties.

In cases involving two-phase liquid or vapor-dominated reservoirs the effects of reinjection on pressures and energy recovery are more difficult to quantify because of the more complex physics involved. In such systems, saturation fronts develop in addition to thermal fronts, with the associated steam condensation and changes in fluid mobilities. Also, the high compressibility of two-phase systems causes relatively slow migration of the pressure front, so that strong transients prevail for a long period of time. Further complications arise in theoretical studies of injection into vapor-dominated systems, where gravity effects become dominant (Calore et al., 1986).

Bodvarsson at al. (1985) examined the effects of reinjection in two-phase liquiddominated systems. They found that fluid reinjection can cause very pronounced increases in production rates and decreases in enthalpy, as shown schematically in Figure 1. These enthalpy changes are not caused by thermal effects associated with cold water injection, but are due to condensation within the fracture system resulting from the increased pressure. The pressure-induced condensation in the fracture system results in increasing liquid saturation, hence, increased mobility of the liquid phase. Higher liquid phase mobility leads to increased flow rates and decreased enthalpies. The lag between the start of injection and the time when a response is observed at the production wells depends primarily on well spacing, fracture porosity, and fracture permeability. If the enthalpy decreases to that of the liquid water in the reservoir, meaning that single-phase liquid conditions have been reached, the flow rate stabilizes and then gradually declines.

Although injection and the associated mobility effects do not increase the steam rate significantly in the short term, it will greatly help in maintaining the steam rate over long periods of time. Pruess et al. (1984) and Bodvarsson et al. (1987) per-

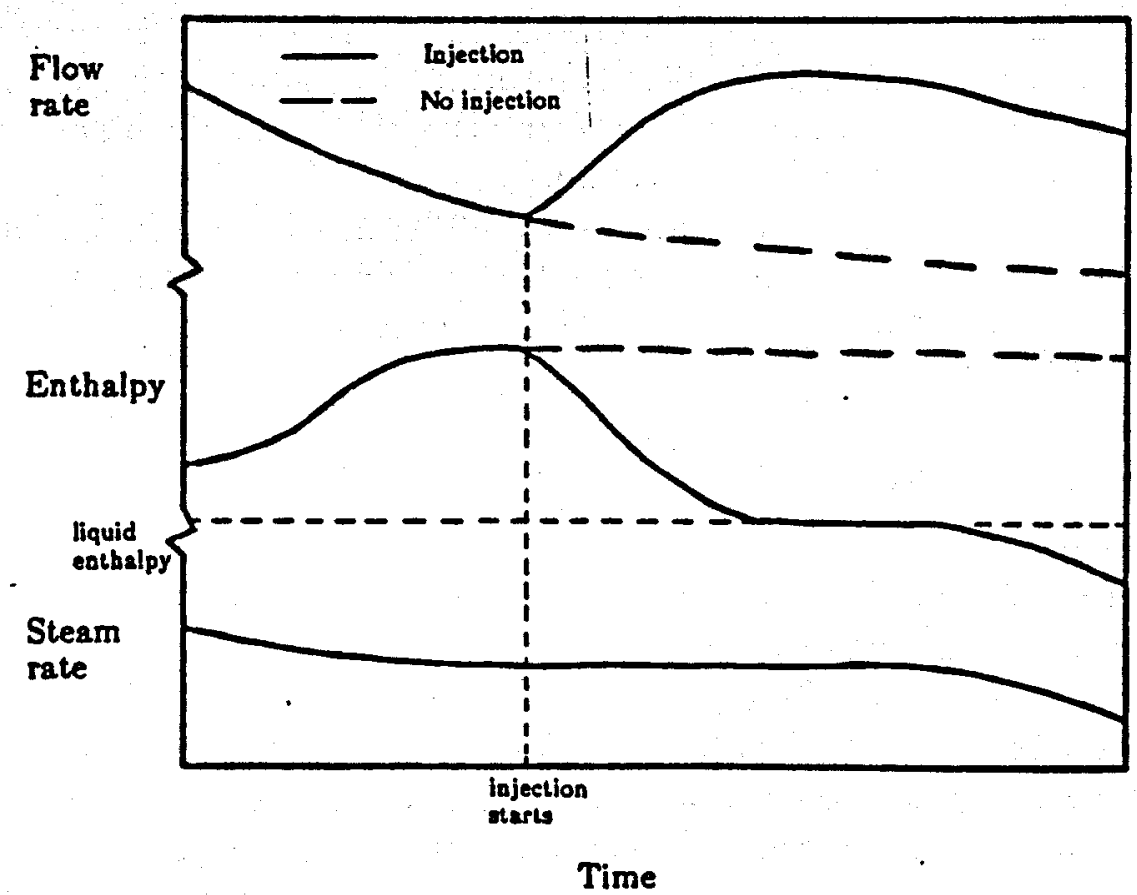

FIGURE 1. Schematic graphs of the effects of injection on flow rate, enthalpies and steam ratey of tho-phase 
formed numerical simulation studies of Krafla, Iceland and Olkaria, Kenya, respectively. They found that injection into these two-phase systems will stabilize the flow rate decline, help maintain steam rates and consequently reduce the need for drilling make-up wells in the future. Figure 2 shows the results obtained for the Olkaria system in Kenya, where it was estimated that 26 make-up wells would be required to maintain $45 \mathrm{MW}_{\mathrm{e}}$ power production over the next 30 years if no injection was used. With $100 \%$ of the produced fluids being reinjected (this of course would require additional fiuids to be imported) the total number of make-up wells was reduced to 11 . A lower injection percentage would decrease the benefits of injection in terms of make-up wells. In these calculations a porous medium approach was used, thus, it was assumed that "fast paths" would not cause rapid thermal degradation at producing wells.

Studies of liquid injection into vapor-dominated systems have been conducted by Schroeder et al. (1980), Calore et al. (1986), and Pruess et al. (1987). Schroeder et al. used a porous medium model and demonstrated the importance of gravity effects during injection into vapor-dominated systems. They also investigated the effects of injection at different depths on the location of the hydrodynamic front. Calore et al. (1986) performed one- and two-dimensional fracture/matrix simulation of injection into a vapor-dominated system with properties similar to those found at Larderello, Italy. They also found that the injection plume tends to move primarily vertically downwards due to gravity, and that temperature and phase fronts for a fractured medium become much more diffuse than those for porous media. The boiling temperature at the surface of the injection plume tends to stabilize with time at a value which is primarily controlled by the injection rate and the reservoir permeability. Larger stabilized boiling temperatures at the edge of the plume result when the

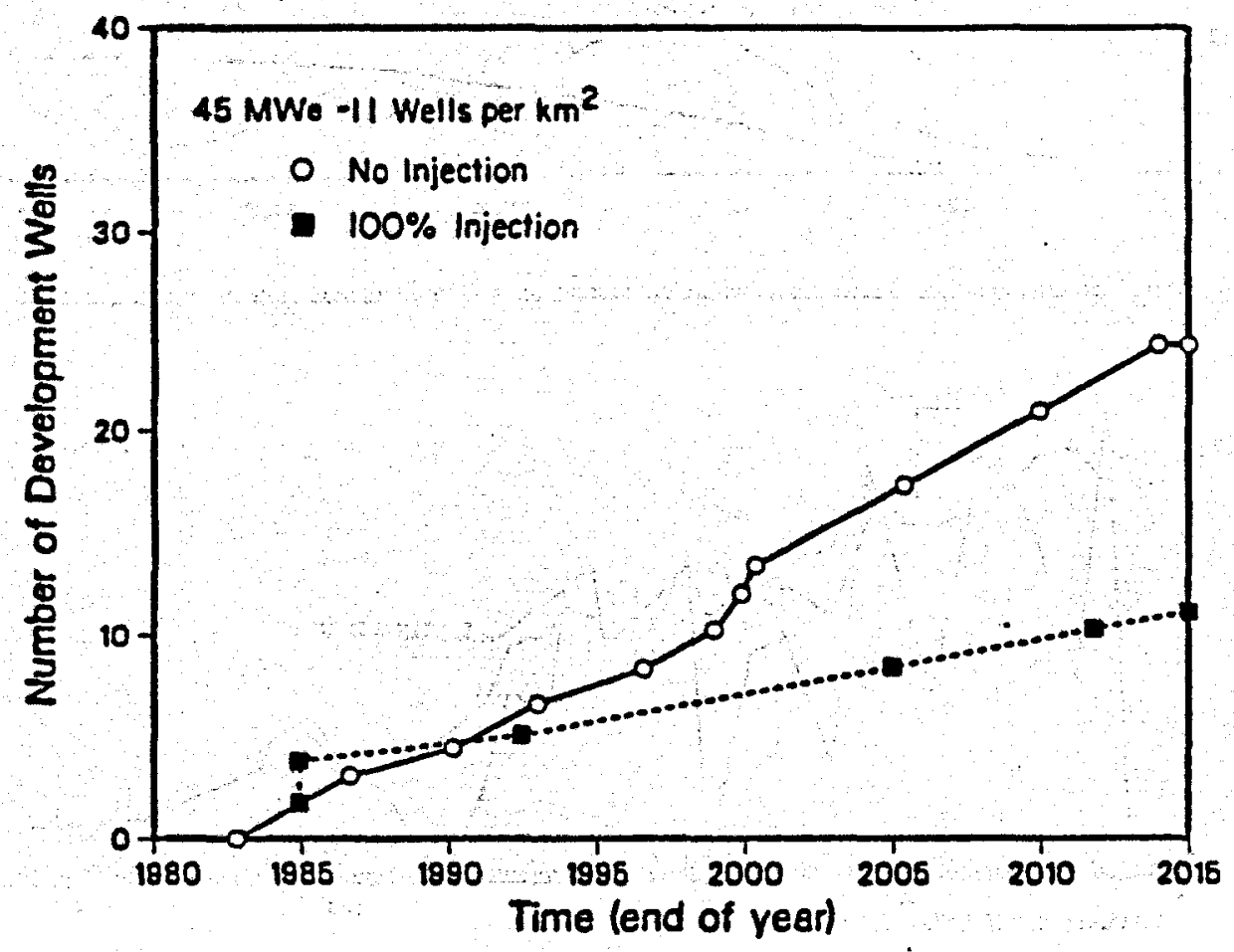

FIGURE 2. Number of development wells needed to maintain $45 \mathrm{MW}_{\mathrm{e}}$ at Olkaria for different well spacing and with $100 \%$ injection (after Bodvarsson et al., 1087). 
injection rate is large and permeabilities are small. Pruess et al. (1987) have analytically evaluated the boiling temperature and the evaporation rate at the edge of the front.

\section{Field Experience}

Perhaps the best documented example of the beneficial effects of reinjection on reservoir pressures is found in data from the Ahuachapán geothermal field in El Salvador. Figure 3 shows the reservoir pressure in Ahuachapán as a function of extraction and injection rates from the reservoir (Vides-Ramos, 1985). It is apparent from the figure that during periods when reinjection is substantial, the pressure decline is more gradual than when reinjection is small (or zero). The pressure decline in Ahuachapán has now reached approximately 15 bars; exploitation has created a significant two-phase zone in the reservoir.

At East Mesa, Magma Power Company has operated a $10 \mathrm{MW}_{\mathrm{e}}$ binary plant since 1980 , with $100 \%$ injection. In the beginning, fluids were injected at the periphery of the field, but recently a fraction of the wastewater has been injected near the center
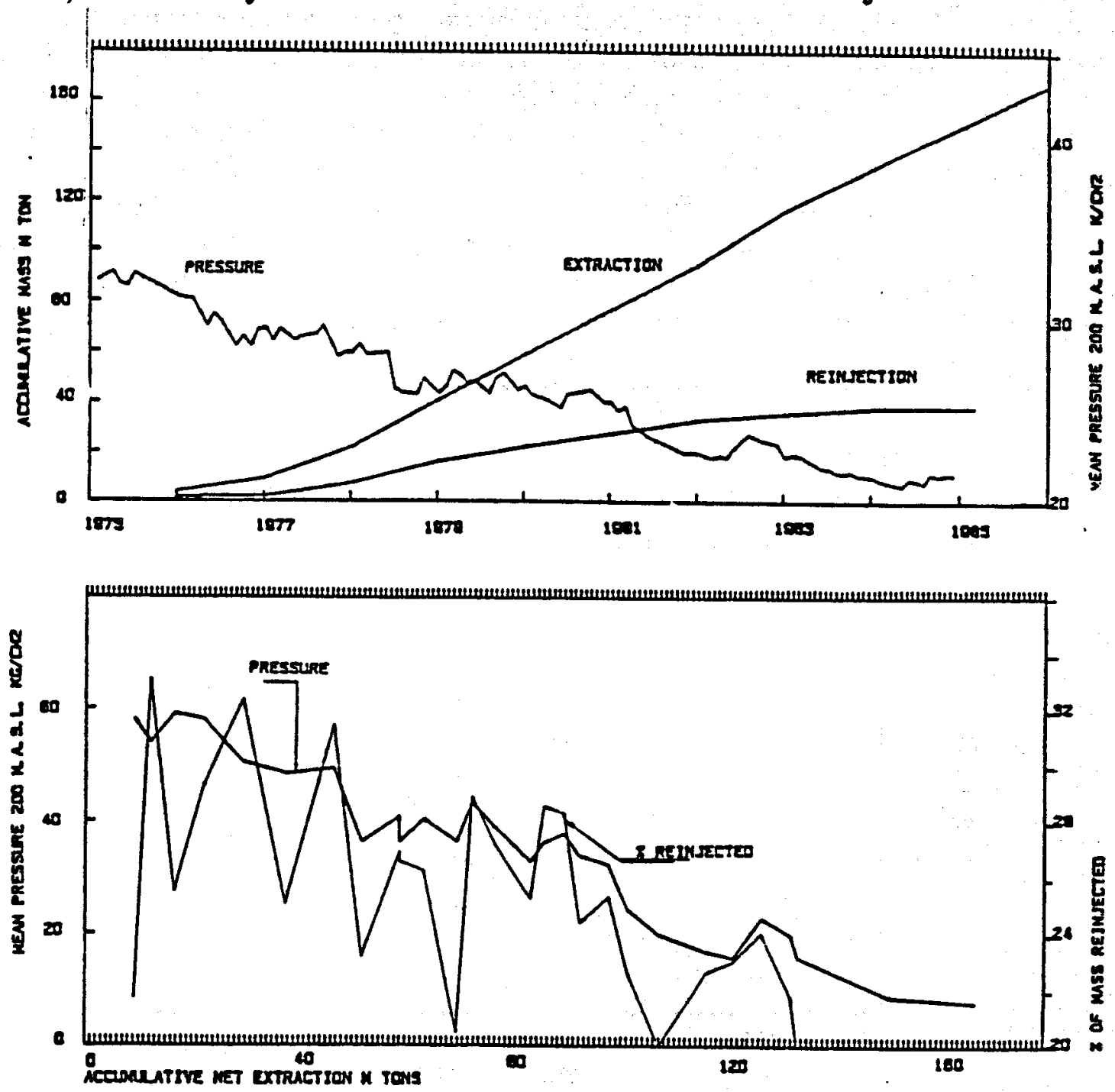

FIGURE 3. Effect of waste water reinjection over mean pressure in Ahuachapan geothermal field (after Vides-Ramos, 1985). 
of the field. This change in injection strategy has helped stabilize reservoir pressures (T. Hendricks, personal communication, 1987).

Reinjection into vapor-dominated reservoirs is documented for Larderello, Italy, and The Geysers, California. Several reinjection experiments have been performed at Larderello since 1979 (Giovannoni, 1981; Nuti et al., 1081; Bertrami et al., 1985), using a single injection well located in the center of the field. Fluids were injected into the "superheated" zone of the reservoir at a rate of $10-50 \mathrm{~kg} / \mathrm{s}$. The injection has resulted in significant increases in steam production at nearby wells (Bertrami et al., 1985). Figure 4 shows the effects of injection on wells W1 and W2 at Larderello, which are located $400-500 \mathrm{~m}$ from the injector. Beneficial effects of reinjection have also been observed at The Geysers (Gulati et al., 1978).
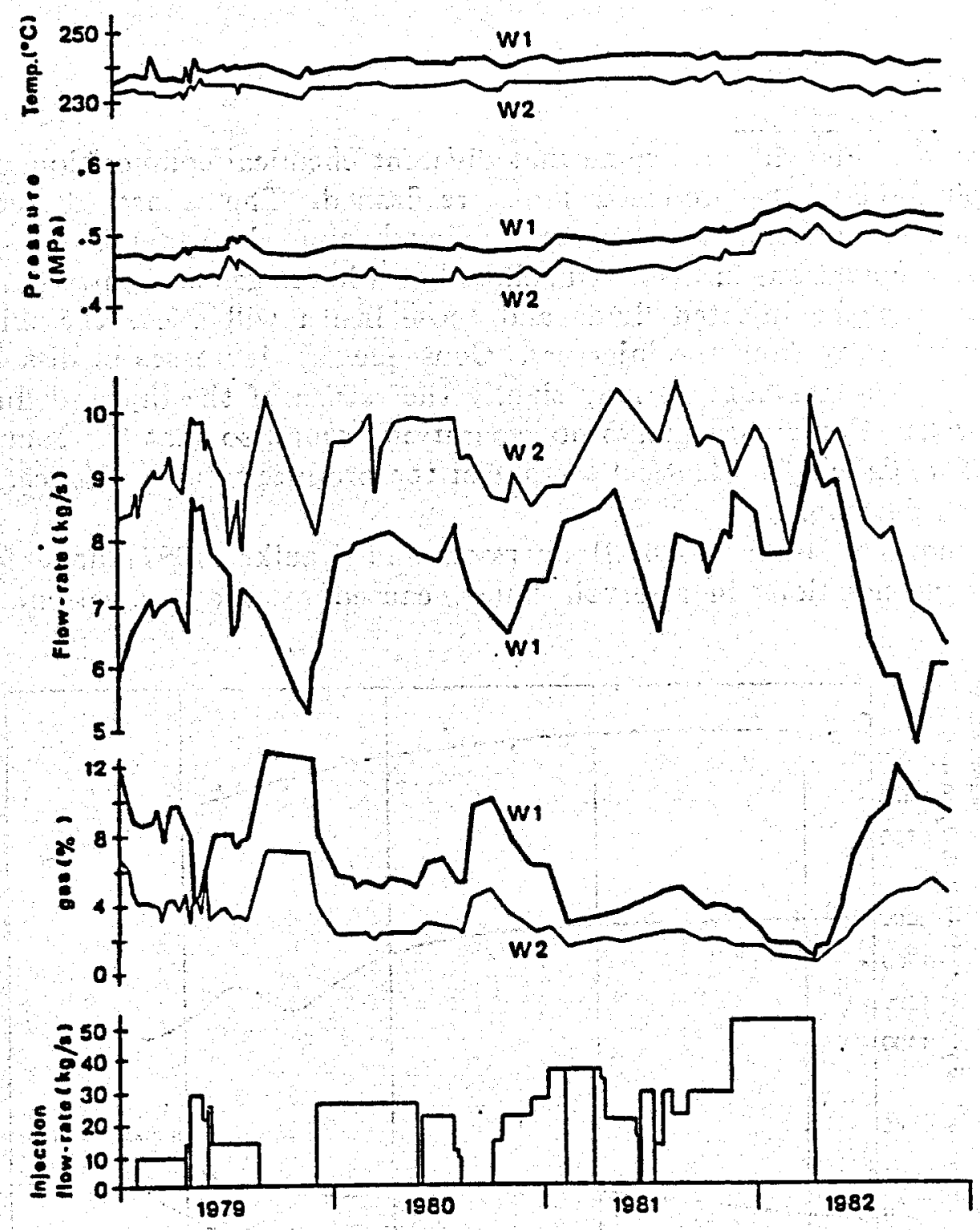

FIGURE 4. Injection rate in well WO at Larderello, Italy. Wellhead pressure, wellhead temperature, flow rate and gas/steam ratio (\% by weight) of wells W1 and W2 (after Bertrami et al., 1085). 
Direct field experience from reinjection into two-phase reservoirs is scarce. As suggested by the theoretical studies discussed above, the most sensitive reservoir parameter in this case is the steam saturation in the reservoir. Reinjection causes large changes in the saturation of the fractures and in the flowing enthalpy of production wells. Figure 5 shows the flow rate and enthalpy of well 404 in the Tongonan field, Philippines (Sarmiento, 1986). The decline in enthalpy is caused by reinjection into well 4R1. Due to mobility effects the decrease in enthalpy (lower liquid saturation of reservoir fluids) will result in increasing liquid production. However, the steam rate flow is almost constant, as Figure 5 shows.

Similar effects have been seen during injection tests at the Krafla field in Iceland (Stefansson et al., 1982), and during reinjection at Bulalo, Philippines (B. Barker, personal communication, 1987).

\section{CHEMICAL EFFECTS}

\section{Theoretical Considerations}

The injected fluids will have somewhat different chemical composition than the in situ reservoir fluids if the produced fluids are flashed. The separated steam will be relatively rich in noncondensible gases, leaving behind the separated water, which has higher concentrations of dissolved solids, but a lower gas content. This chemical contrast between the injected fluids and those insitu will cause the migration of chemical fronts away from the injectors. Consequently, increases in dissolved solids or decreases in the gas content may signify the return of the injected fluids at the producing wells. For binary plants no separation occurs, so that the composition of the injected fluids will be identical to that of the produced fluids. Hence, no chemical fronts will develop.

Recent studies (Gaulke, 1986; Bodvarsson and Gaulke, 1987) have found that lower gas concentrations in reservoir fluids, caused by the reinjection, may have

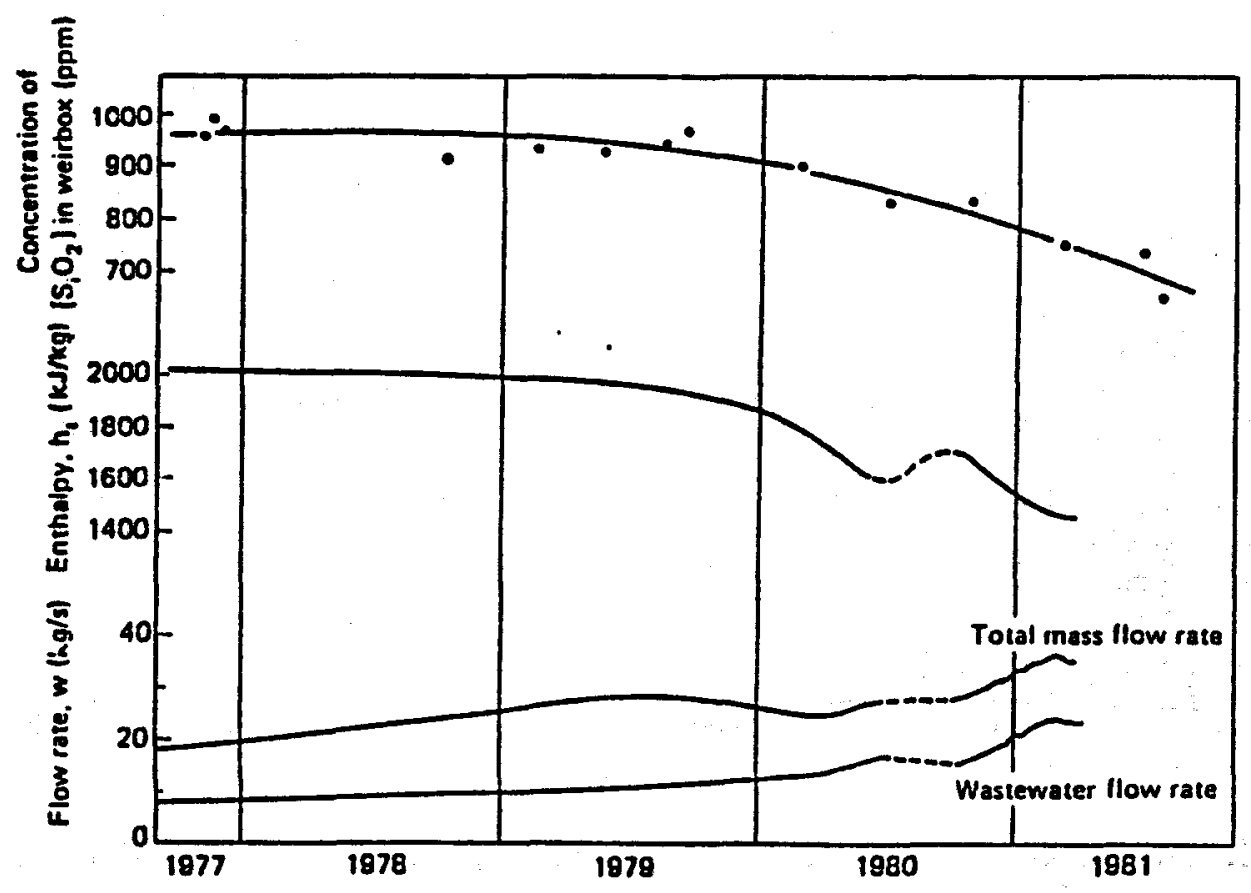

FIGURE 5. Discharge history of well 404 in Tonganan, Philippines showing output changes (after Sarmiento, 1986). 
beneficial effects on fluid mass recovery from the tight matrix blocks. The mass recovery from matrix blocks depends upon various factors, such as the average pressure drop, matrix porosity, the reservoir temperature and the concentration of gas in fluids flowing within the fracture system feeding the wells. Theoretical studies have shown that lowering the concentration of noncondensible gases flowing in the fracture system perhaps by means of injection may increase the mass recovery from the matrix blocks and consequently increase extraction rates at producing wells. This is because in order to establish a total thermodynamic equilibrium between fractures and the rock matrix, pressure, temperature and partial pressure of the gas must be equal in the two continua. Thus, if the concentration of noncondensible gases flowing in the fractures is reduced, fluids containing gases must flow from the matrix to the fractures in order to equilibrate the gas partial pressure. Theoretical studies have found this effect to be quite significant, especially for low-enthalpy wells (Gaulke, 1986; Bodvarsson and Gaulke, 1987).

Figure 6 shows computed flow rate and mass fraction of $\mathrm{CO}_{2}$ for a composite system with gas rich fluids near the production well and gas-free fluids farther away. This type of system will develop if relatively gas-free fluids are injected. The figure shows that the decline in the concentration of $\mathrm{CO}_{2}$ in the produced fluids stabilizes the flow rate decline of the well. This is partly a result of fluid recharge from the matrix to the fractures caused by the imbalance in $\mathrm{CO}_{2}$ concentrations from the gas-free injected fluids.

Well injectivities are of concern in many geothermal fields, because injectivity decline may require higher injection pressures or new injection wells to be added. Injectivity decline can be caused by various processes, including scaling in the wellbore or the reservoir, particle plugging due to fine-grained material in the injected fluids or clay swelling if fluids with low concentrations of dissolved solids are injected. If the waste water is not treated prior to injection it is often recommended

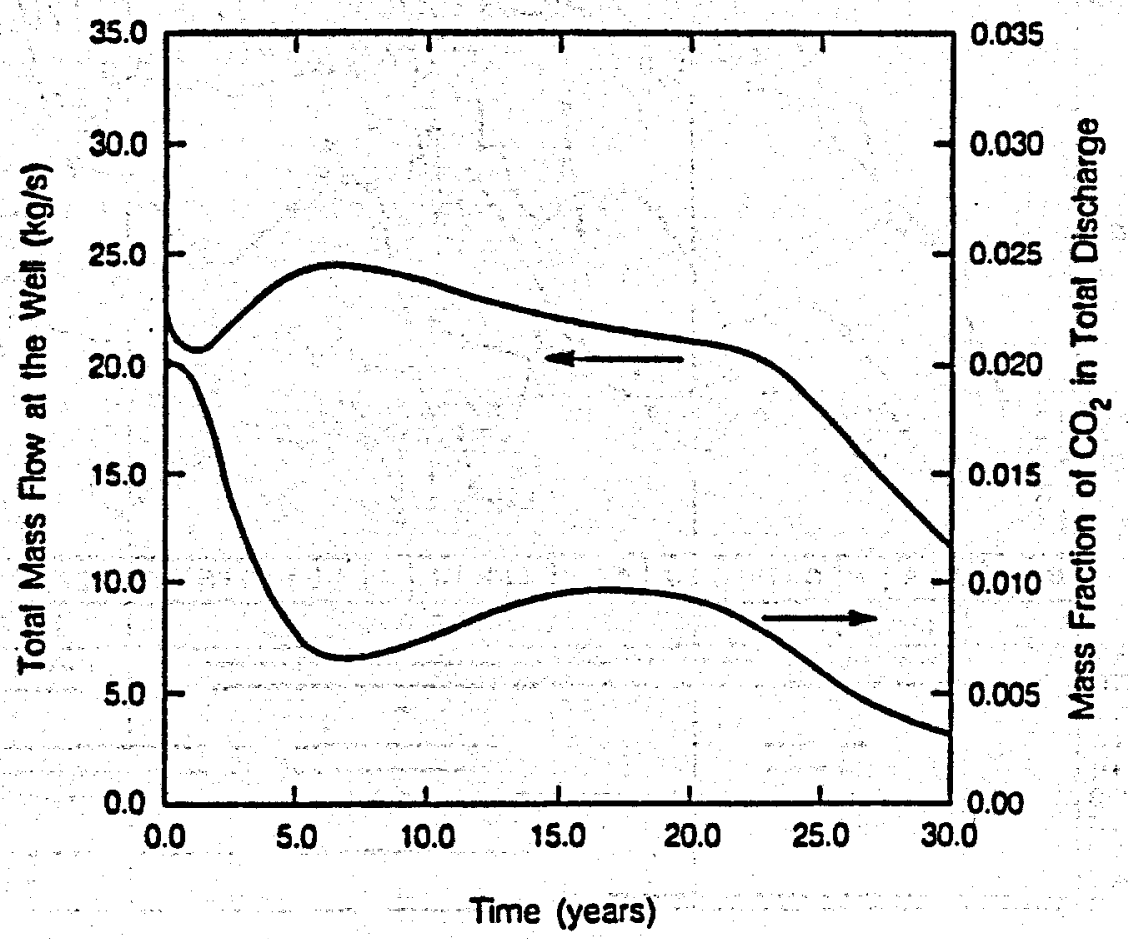

FIGURE 6. Theoretical results of changes in mass flow rate and total mass fraction of $\mathrm{CO}_{2}$ with time for a case involving injection (after Gaulke, 1986). 
to keep the temperature of the injected water as high as possible to avoid supersaturation of silica in the brine and consequential scaling in the wellbore or the reservoir (Einarsson et al., 1975). It is also important to prevent exposure of the brine to the atmosphere because of oxygen dissolution, which can lead to corrosion problems. These types of problems and solutions are addressed in a recent overview of injection water treatment (Kindle et al., 1984).

\section{Field Experience}

Perhaps the best data published on the effects of injection on the concentrations of dissolved solids at production wells are those presented by Harper and Jordan (1985) from the Palinpinon field in the Philippines. After three years of production of 45 $\mathrm{MW}_{\mathrm{e}}$, increases in chloride are observed in most production wells (Fig. 7). As the chemical composition of both injected and produced fluids is monitored with time, these data allow for the determination of the fraction of injected water in production well fluids (Fig. 8). It is interesting to note that all of the fluids produced from some of the wells have been reinjected ( $100 \%$ returns). However, the average value for the entire field is about $30 \%$ returns.

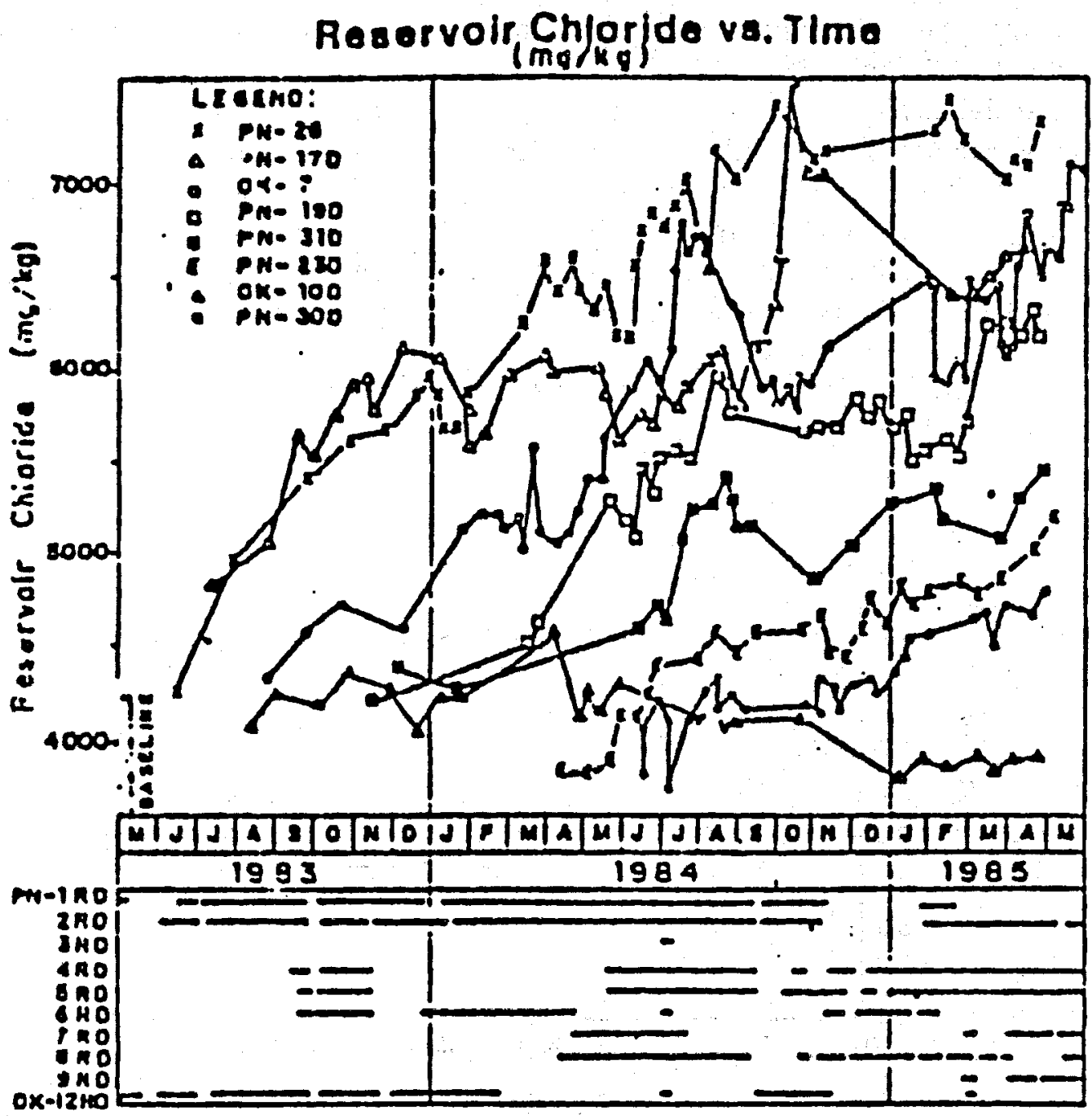

FIGURE 7. Changes in chloride concentration with time for wells at Palinpinon, Philippines (after Harper and Jordan, 1985). 


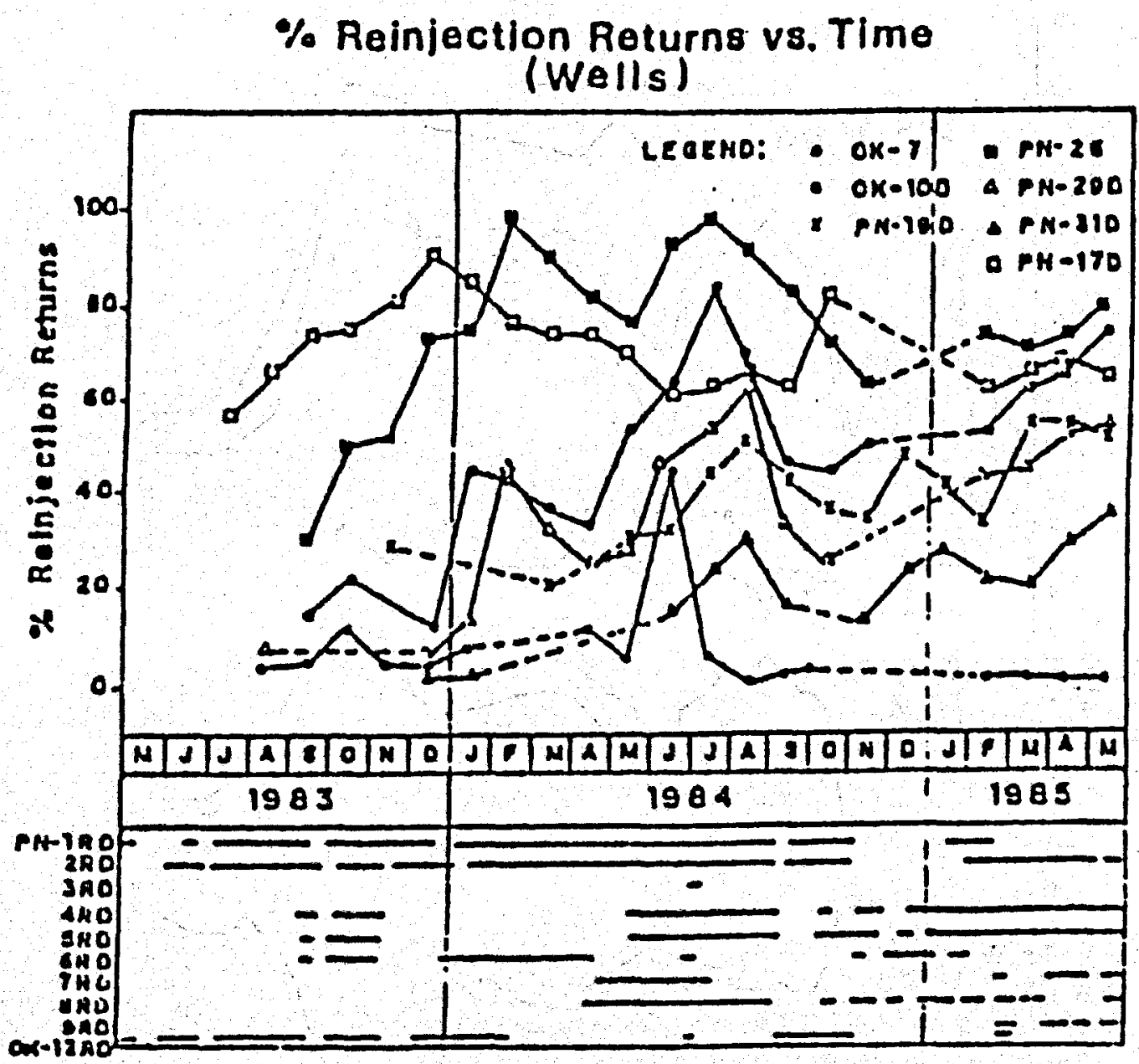

ReInjection wolls ullization Alstory

FIGURE 8. Percentage of produced fluids that have been reinjected for wells in Palinpinon, Philippines (after Harper and Jordan, 1985).

Increases in the total dissolved solids due to reinjection have also been observed in other geothermal fields in the Philippines, including Tongonan (Sarmiento, 1086), Bulalo, and Tiwi (B. Barker, personal communication, 1987), as well as Ahuachapán El Salvador (Horne, 1982) and Roosevelt Hot Springs (S. Johnson, personal communication, 1087).

In the reinjection experiments at Larderello, Italy (Giovannoni et al., 1981; Nuti et al., 1881; Bertrami et al., 1985), stable isotopes were used to determine the recovery of injected fluid at the production wells. It was found that more than $85 \%$ of the injected water was vaporized and recovered in the production wells. Figure $\theta$ shows the transient concentrations of isotopes and gases correlated with the injection rate during the 1970-82 test period (Bertrami et al., 1985). In the reinjection test at Larderello, the gas concentration during reinjection was only $70 \%$ of the gas concentration when no injection was occurring (Bertrami et al., 1085; Figure 8). Decreases in noncondensible gases have also been observed in those wells in Palinpinon where increases in $\mathrm{Cl}$ content have been seen (Harper and Jordan, 1985).

In the above discussion, chemical movement due to natural tracers in the injected fluids were considered. At many geothermal fields tracer tests involving artificial (introduced) tracers have been conducted; some of these are summarized by Horne 

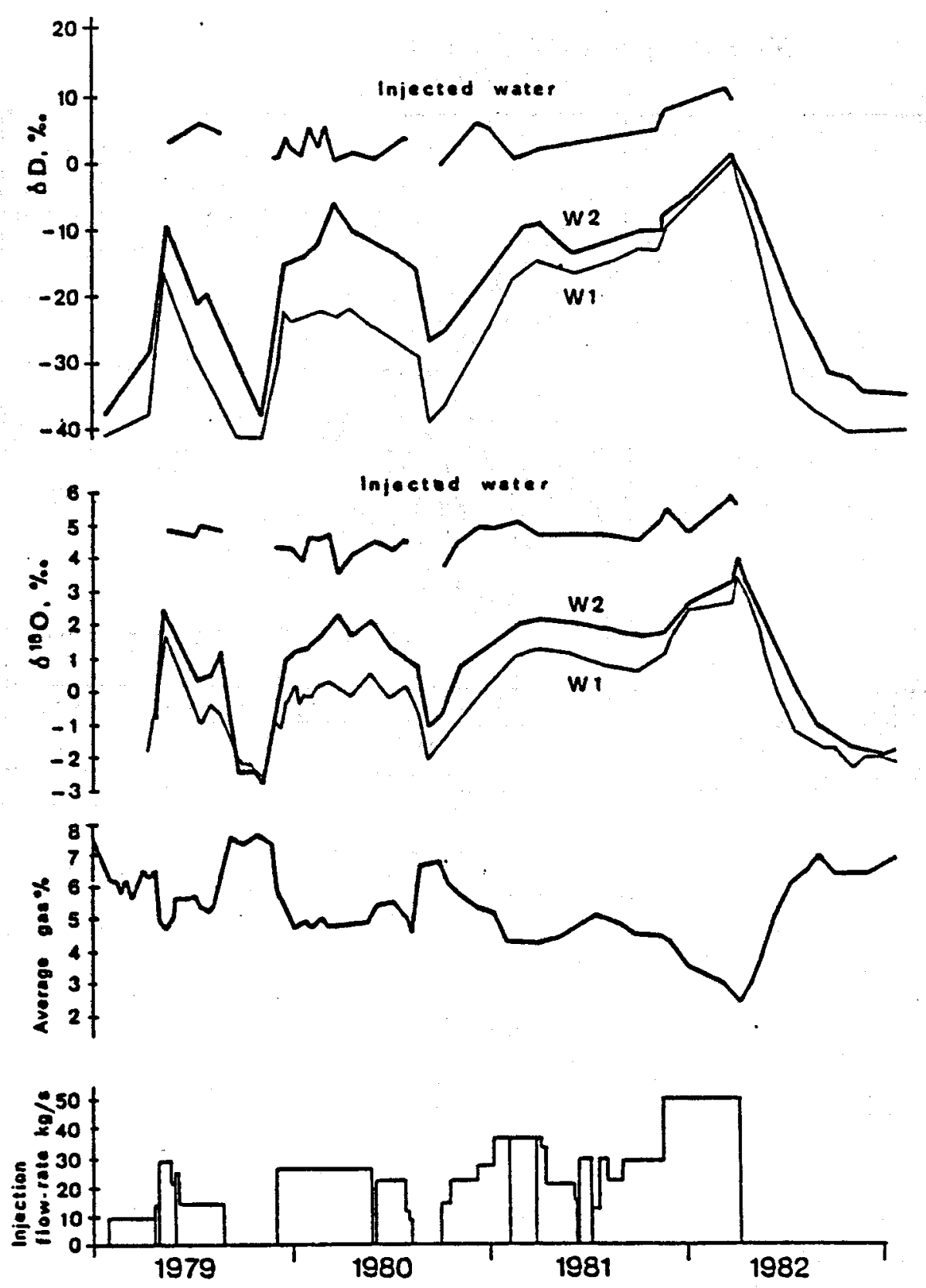

FIGURE 9. Variations in the isotopic composition of the fluid discharged by Larderello wells w1 and w2, and of the injected water. Trend of average gas content of the monitored wells (after Bertrami et al., 1085).

(1982; 1985), Bixley and Grant (1979), and Sarmiento (1986). The results of these tracer tests have shown very high tracer velocities at various fields as shown in Table 1, which was compiled by Pruess and Bodvarsson (1984) using data from Hayashi et al. (1978), Horne (1082) and Fossum and Horne (1082). The table shows that tracer velocities on the order of 1 to $10 \mathrm{~m} / \mathrm{hr}$ are not uncommon. Tracer test data are very useful in characterizing the fracture/fault system that prevails at a given site and for consideration when a reinjection scheme is being designed.

Chemical deposition (and scaling) and fluid injectivity problems have been identified at various geothermal fields. The geothermal waste water is frequently supersaturated with respect to various chemical components, silica and calcite being 
Table 1. Selected tracer data from geothermal fields with preferential flow paths (from Pruess and Bodvarsson, 1084).

\begin{tabular}{|c|c|c|c|c|c|c|}
\hline $\begin{array}{c}\text { Geothermal } \\
\text { Field }\end{array}$ & $\begin{array}{l}\text { Injection } \\
\text { Well }\end{array}$ & $\begin{array}{c}\text { Prod./Obs. } \\
\text { Well }\end{array}$ & $\begin{array}{l}\text { Injection } \\
\text { Rate } \\
(\mathrm{kg} / \mathrm{s})\end{array}$ & $\begin{array}{l}\text { Distance of } \\
\text { Tracer Recovery } \\
\text { (m) }\end{array}$ & $\begin{array}{c}\text { Average Linear } \\
\text { Velocity } \\
(\mathbf{m} / \mathbf{h r})\end{array}$ & $\begin{array}{c}\text { Cumulative } \\
\text { Recovery } \\
(\%)\end{array}$ \\
\hline Wairakei & $\begin{array}{l}\text { WK80 } \\
\text { WK107 } \\
\text { WK101 }\end{array}$ & $\begin{array}{l}\text { WK116 } \\
\text { WK76 } \\
\text { WK108 } \\
\text { WK24 } \\
\text { WK48 } \\
\text { WK121 } \\
\text { WK103 } \\
\text { WK116 }\end{array}$ & & $\begin{array}{l}500 \\
145 \\
230 \\
500\end{array}$ & $\begin{array}{r}2.7 \\
0.7 \\
1.1 \\
22.0 \\
7.0 \\
8.0 \\
1.3 \\
2.0\end{array}$ & $\begin{array}{l}3.7 \\
1.3 \\
6.0\end{array}$ \\
\hline $\begin{array}{l}\text { Ohaaki } \\
\text { (Broadlands) }\end{array}$ & $\begin{array}{l}\text { BR13 } \\
\text { BR28 } \\
\text { BR33 }\end{array}$ & $\begin{array}{l}\text { BR23 } \\
\text { BR25 } \\
\text { BR11 } \\
\text { BR8 }\end{array}$ & $\begin{array}{l}41.7 \\
41.7 \\
83.3\end{array}$ & $\begin{array}{r}270 \\
75\end{array}$ & $\begin{array}{l}0.4 \\
0.8 \\
0.4\end{array}$ & $\begin{array}{r}6.0 \\
12.0 \\
5.0\end{array}$ \\
\hline Hatchobaru & $\begin{array}{l}\text { HR17 } \\
\mathrm{H} 6 \\
\mathrm{H}-9 \mathrm{R} \\
\mathrm{H} 3\end{array}$ & $\begin{array}{l}\text { H7 } \\
\text { H3 } \\
\text { H14 } \\
\text { H4 } \\
\text { H13 } \\
\text { H13 } \\
\text { H4 } \\
\text { H6 } \\
\text { H7 }\end{array}$ & $\begin{array}{l}97.2 \\
11.1\end{array}$ & $\begin{array}{l}140 \\
135 \\
180\end{array}$ & $\begin{array}{r}78.0 \\
16.0 \\
35.0 \\
8.0 \\
2.0 \\
62.0 \\
6.1 \\
33.8 \\
9.0\end{array}$ & 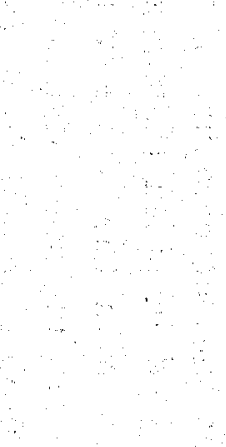 \\
\hline Otake & OR-2 & $\begin{array}{l}0-8 \\
0-9 \\
0-10\end{array}$ & & $\begin{array}{l}125 \\
203 \\
140\end{array}$ & $\begin{array}{l}0.2 \\
0.3 \\
0.2\end{array}$ & 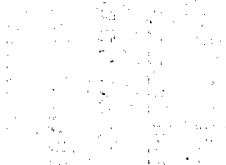 \\
\hline Tongonan & $4 \mathrm{RI}$ & $\begin{array}{l}404 \\
401 \\
108\end{array}$ & $\therefore$ & $\begin{array}{l}\approx 400 \\
\approx 200 \\
\approx 200\end{array}$ & $\begin{array}{l}57.0 \\
30.0 \\
22.0\end{array}$ & $\begin{array}{l}11.5 \\
2.8 \\
2.0\end{array}$ \\
\hline
\end{tabular}


the most important. Experience to data has indicated that scaling problems can mostly be alleviated if the separator water is injected directly using a closed system. This ensures that the temperature of the injected water is high and the fluids are often undersaturated in silica (Einarsson et al., 1975). More scaling problems are usually associated with the waste water from the cooling towers, which is often discharged into a settling pond and then injected under ambient conditions.

Silica scaling problems that have resulted in decreases in injectivity have been documented for several fields, including Hatchobaru and Otake in Japan (Horne, 1982; Inoue and Shimada, 1985). Furthermore, serious problems with scaling in the surface pipelines at these fields have been observed.

Other factors causing injectivity problems in wells include suspended solids in the injected fluids and low formation permeability. Fluids are injected at very high injection pressures at Heber, California (500 - 700 psi), primarily because of the low permeability of the injection zone (Hoang, personal communication. 1987). Injectivity decline has also been observed due to formation plugging of fine-grained materials or silica scaling. The problem is reduced by adding acid to the injected fluids and backflowing the wells periodically, after which the injectivity seems to fully recover. Similar injectivity problems have been observed at Salton Sea (M. Barnes, personal communication, 1987), East Mesa, Imperial Valley (M. Barnes, personal communication, 1987), and Tiwi, in the Philippines (B. Barker, personal communication, 1087).

In many geothermal fields the short term injectivity has been found to increase with time. This has been observed in several fields in Iceland, New Zealand (Horne, 1982), and Mexico (Benson et al., 1987). This increase in injectivity has been explained by thermal contraction of the reservoir rocks (Stefansson and Steingrimsson, 1980; Benson et al., 1987). However, for many wells this trend of injectivity enhancement is reversed later on if the injection activity continues.

\section{THERMAL INTERFERENCE EFFECTS}

Theoretical Considerations

An important concern in the development of a reinjection scheme is the migration of the cold water front away from the injection wells, and possible premature thermal breakthrough at producing wells. In some cases the waste fluids are injected in different hydrological environment from the producing layers, and the possibility of thermal breakthrough is remote. For example, at several fields the fluids are injected into shallow permeable aquifers above the primary geothermal reservoir. However, in most cases fluids are injected into the producing reservoir, and consequently the shortcutting of cold fluids through iast paths (faults or fractures) is of concern.

For geothermal reservoirs located in sedimentary rocks where the primary permeability is matrix dominated, the migration of the cold water front away from an injection well is fairly well understood through the work of Lauwerier (1955) and Bodvarsson (1972; 1974). The basic theory developed by Lauwerier (1955) and Bodvarsson (1974) can readily be extended to a system with multiple production and injection wells and the temperature changes with time at the production wells predicted (Gringarten and Sauty, 1975).

The geothermal reservoirs in the Salton Trough (e.g., Heber, Brawley, East Mesa, Salton Sea, Cerro Prieto, Mexico) are located in sedimentary rocks, primarily layers of sandstones and shales. The matrix permeability is significant, so that for most 
cases porous medium models may be applied in estimating the migration of thermal fronts. There is growing evidence, however, that fluid movement in these fields is also controlled to some extent by major faults and fracturing within the sedimentary units (Hoang et al., 1987).

Most geothermal reservoirs are fracture-dominated, with high fracture permeabilities and low matrix permeabilities. For these types of reservoirs, predictions of the movement of the cold water front are much more difficult to make, primarily because detailed data on the characteristics of the fracture system are needed. Such data as apertures, orientations, densities, and sizes of fractures and faults will be regimed to compute fluid flows within the fractures. The effective surface area between the fracture and the matrix blocks per unit rock volume is the parameter that primarily controls the movement of the cold water front. The larger the surface area the more heat will be conducted from the matrix, heating up the cooler fracture fluids.

Various simplified analytical models have been developed for estimating the cold water movement in fractured rocks. Most of these models assume that the rock matrix is impermeable, but that it conducts heat to the fracture fluids: Bodvarsson and Tsang (1082) developed a model for the evaluation of cold water injection into a series of horizontal fractures. They found that initially the cold water front moves rapidly away from the injection well, but as the surface area between the fracture and the matrix increases with distance from the well, the fluid gains significant conductive heat from the matrix, and the movement of the front slows considerably. Before the effects of thermal conduction are significant the cold water front in the fractures migrates at an areal speed proportional to $r^{2} / t$, similar to a porous slab. When thermal conduction starts to govern the advance of the cold water front, the movement is much slower or proportional to $\mathrm{r}^{4} / \mathrm{t}$. At late time, for a system involving equally spaced fractures the heat flow symmetry boundary is felt, resulting again in $r^{2} / t$ dependence of the migration of the cold water front. When these conditions are reached the system behaves thermally as an equivalent porous medium with a thickness $D$. Similar equations have been derived for naturally fractured reservoirs by Kasameyer and Schroeder (1075) and Bodvarsson and Lai (1082).

Laboratory studies of fractured media have also yielded important results of energy extraction rates from matrix blocks (Lam et al., 1085; Hosca and Okandan, 1986). Such studies help verify the validity of the analytical models and provide detailed information on the temperature distribution in the matrix blocks.

In general, the migration of the chemical front that is revealed by the tracer data cannot be correlated with the advance of the thermal front in fractured systems. The migration of the hydraulic front depends primarily on the pore volume available for flow, whereas the migration of the thermal front is controlled by the surface area of the fracture walls that are available for conductive heat transfer from the rock matrix. However, if it is possible to develop a flow model for the fracture system from the available geological data, one can then develop relationships between the migration of the chemical and thermal fronts. For example, Pruess and Bodvarsson (1984) have developed the correlations shown in Figure 10 for geothermal systems with vertical fractures. From the results of tracer tests, the fluid residence time and the effective fracture aperture, $w$, can be determined. The curves in Figure 10 can then be used to estimate the time of thermal breakthrough. It is quite clear from this figure that for a given residence time, the larger the effective aperture, the shorter the time period until thermal breakthrough occurs. This is to be expected 


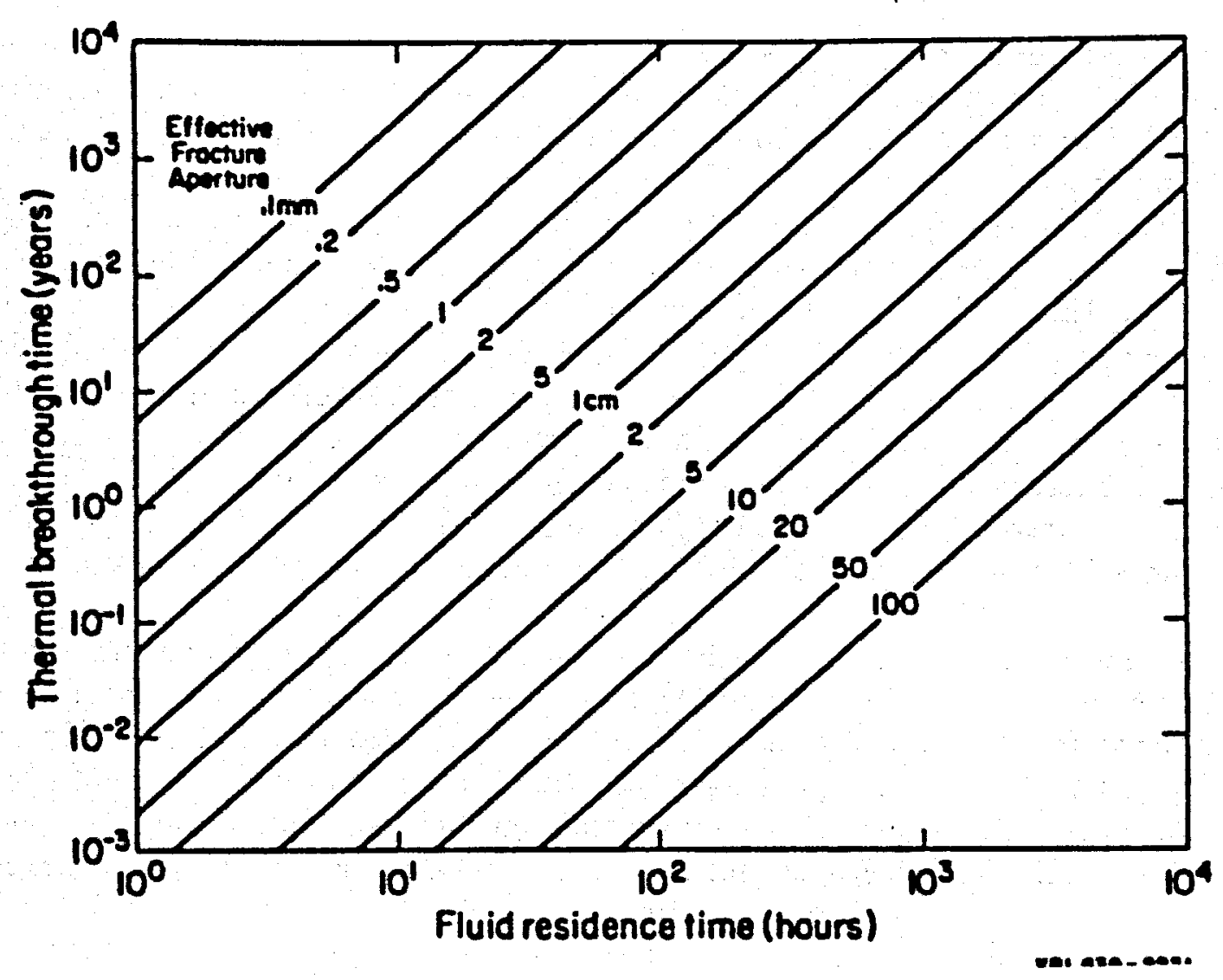

FIGURE 10. Correlation curves for fluid residence time and thermal breakthrough time for vertical fractures (after Pruess and Bodvarsson, 1984).

because the larger the aperture, the smaller the ratio of the surface area to volume for the fracture becomes, and the more rapid the movement of the thermal front.

The above discussion has centered on the problems of designing a reinjection system, but is is also important to consider the remedial actions that are possible during the operation of such a system. Pruess and Bodvarsson (1984) used a vertical fracture model and found that the thermal recovery in the production wells was very rapid when the injector was shut-in. This suggests that even if thermal breakthrough occurs, the cooling effects are reversible and the system can be restored in a reasonably short period of time.

\section{Field Experience}

Thermal breakthrough of cold injected fluids into producing wells has been observed in several geothermal fields. Here we refer to thermal breakthrough as an enthalpy decline which is not associated with a flow rate increase, hence, due to thermal effects rather than pressure effects. Horne (1982) suggests that thermal breakthrough has occurred in various fields in Japan based on tracer data and other evidence. Inoue and Shimada (1985) showed that thermal breakthrough has occurred in Hatchobaru as evidenced by declining steam rates and declining temperature in well H4. The cold water breakthrough is believed to be due to the fact that the production well, H4, is completed in the same faults as several injection wells. Apparently, some other wells in the field have also been thermally degraded, although many of the wells show no adverse temperature decline due to injection. 
Thermal breakthrough of cold injected fluids at production wells has been observed in a few wells in Japan, the Philippines, and EI Salvador. In most cases the cooling effects have been rectified by shutting in the "problem-causing" injection wells.

It appears from reviewing the literature on injection performance that there is no universal rule regarding proper locations of injection wells. This depends to a large degree on the characteristics of the field in question and the main purpose of the injection scheme (disposal or pressure maintenance). Peripheral injection is currently used in most geothermal fields worldwide.

\section{ACKNOWLEDGMENTS}

The authors thank M. Lippmann for critical review of this work. This work was supported through U.S. Department of Energy Contract No. DE-AC03-76SF00098 by the Assistant Secretary for Conservation and Renewable Energy, Office of Renewable Technology, Division of Geothermal Technology.

\section{REFERENCES}

Benson, S.M., Daggett, J.S., Iglesias, E., Arellano, V. and Ortiz-Ramirez, J., 1087, Analysis of thermally induced permeability enhancement in geothermal wells, Proc. 12th Workshop on Geothermal Reservoir Engineering, Stanford University, Stanford, California, in press.

Bertrami, R., Calore, C., Cappetti, G., Celati, R. and D'Amore, F., 1085, A threeyear recharge test by reinjection in the central area of Larderello field: Analysis of production data, Geothermal Resources Council Trans., vol. 8, part II, pp. 203298.

Bixley, P.E. and Grant, M.A., 1070, Reinjection testing at Broadlands, Proc. 5th Workshop of Geothermal Reservoir Engineering, Stanford University, Stanford, California, pp. 41-47.

Bodvarsson, G., 1972, Thermal problems in the siting of reinjection wells, Geothermics, vol. 1, no 2.

Bodvarsson, G., 1974, Geothermal resource energetics, Geothermics, vol. 3, pp. 83-02. Bodvarsson, G.S. and Gaulke, S.W., 1987, Effects of noncondensible gases on fluid recovery in fractured geothermal reservoirs, SPE Reservoir Engineering, vol. 2, no. 3, pp. 335-342, LBL-21112.

Bodvarsson, G.S. and Lai, C.H., 1982, Studies of injection into naturally fractured reservoirs, Geothermal Resources Council Trans., vol. 6, pp. 245-248, LBL-14519.

Bodvarsson, G.S. and Tsang, C.F., 1982, Injection and thermal breakthrough in fractured geothermal reservoirs, JGR, vol. 87, no. B2, pp. 1031-1048.

Bodvarsson, G.S., Pruess, K. and O'Sullivan, M.J., 1985, Injection and energy recovery in fractured geothermal reservoirs, Soc. Pet. Engr. Jour., vol. 25, no. 2, pp. 303-312, LBL-15344.

Bodvarsson, G.S., Pruess, K., Stefansson, V., Bjornsson, S. and Ojiambo, S.B., 1087, East Olkaria geothermal field, Kenya, 2. Predictions of well performance and reservoir depletion, Journal of Geophysical Research, vol. 02, no. B1, pp. 541-554.

Calore, C., Pruess, K. and Celati, R., 1086, Modeling studies of cold water injection into fluid-depleted vapor-dominated geothermal reservoirs, Proc. 11th Workshop on Geothermal Reservoir Engineering, Stanford University, Stanford, California, report SGP-TR-93, pp. 161-168, LBL-21252.

Dobbie, T.P. and Menzies, A.J., 1970, Geothermal wastewater reinjection trials, 
Cooling has also been observed in production well Ah-29 in Ahuachapán, El Salvador (Vides-Ramos, 1985). The well, which is located only $150 \mathrm{~m}$ from an injector, cooled by approximately $30^{\circ} \mathrm{C}$ from 1975 to 1982 . During this period single-phase liquid water fed the well. Some cooling of the two-phase wells in Ahuachapán has been observed also, due to boiling in the formation rather than cooling from reinjection. Several wells in Bulalo and Tiwi in the Philippines have experienced cooling due to thermal interference from injectors (B. Barker, personal communication, 1987).

In most cases thermal interference due to injection has been rectified by shutting in the injection wells involved. This has been done, for example, in various fields in Japan, El Salvador and the Philippines. In Hatchobaru the thermal problems with injection are partly solved by transporting some of the waste water to Otake for injection (Inoue and Shimada, 1985). Some field data support theoretical calculations indicating that production wells which have been thermally degraded will recover rapidly in temperature. One well in Ahuachapán was used for injection for two years, but recovered sufficiently in a few months to become a good producer.

\section{SUMMARY}

Reinjection is currently used in many geothermal fields in the world, primarily as a means for waste water disposal. In some areas reinjection is necessary to maintain pressures and prevent subsidence, which is very important, for example, in many geothermal fields in the Imperial Valley, California. Both theoretical studies and field data clearly show beneficial effects of reinjection related to pressure maintenance. For several geothermal projects currently under development, pressure support from reinjection is essential for the success of these projects in the future.

Theoretical studies of injection into two-phase reservoirs have predicted strong mobility effects causing enthalpy decline and increases in production rates. These results have been subsequently verified by field data, which often are misinterpreted as being due to thermal effects, when in fact they are pressure-related. Injection into vapor-dominated systems has shown direct benefits as much of the injected water vaporizes and is produced, thus, extracting heat from the reservoir rocks.

Chemical effects associated with injection include injectivity decreases due to scaling and the migration of chemical fronts in the reservoir, because the injected fluids often have different chemical composition from those in-situ. It is often found that well injectivities increase during the first few years of injection, presumably due to thermal contraction of the reservoir rocks enhancing the near-well permeabilities. Later on, however, the injectivity generally declines due to scaling in or near the wellbore or formation plugging due to suspended fine-grained materials suspended in the waste water. Injectivity and scaling problems are minimized if the fluids are injected directly from the separators using a closed system.

Predictions of the migration of cold water fronts in fractured reservoirs are difficult to make, because so little information is available regarding preferential flow paths and the reservoir fracture characteristics. Simple analytical and semianalytical solutions can be used for idealized fracture systems in an attempt to predict the movement of the cold injected fluids. More detailed evaluation can be performed using numerical simulations. However, it seems that the limited data base regarding fracture and fault characteristics of geothermal systems will always cause large uncertainties in the predicted results. 
Mahiao reservoir, Republic of The Philippines, Transactions, Geothermal Resources Council, vol. 3, pp. 160-172.

Einarsson, S.S., Vides, A. and Cueller, G., 1975, Disposal of geothermal waste water by reinjection, Proc. Second United Nations Symposium, San Francisco, CA, vol. 2, pp. 1349-1364.

Ellis, A.J. and Mahon, W.A.J, 1077, Chemistry and geothermal systems, Academic Press, New York, 392 pp.

Fossum, M.P. and Horne, R., 1082, Interpretation of tracer return profiles at Wairakei geothermal field using fracture analysis, Trans. Geothermal Resources Council, vol. 6, pp. 261-264.

Gaulke, S., 1986, The effects of $\mathrm{CO}_{2}$ on reservoir behavior of geothermal systems, M.S. Thesis, University of California, Berkeley, Lawrence Berkeley Laboratory report LBL-22720, 135 pp.

Giovannoni, A., Allegrini, G. and Cappetti, G., 1081, First results of a reinjection experiment at Larderello, Proc. 7th Workshop on Geothermal Reservoir Engineering, Stanford University, Stanford, California, SGP-TR-55, pp. 77-84.

Grant, M.A., 1977, Permeability reduction factors at Wairakei, AICHE-AIME Heat Transfer Conference Paper 77-HT-52.

Gringarten, A.C. and Sauty, J.P., 1975, A theoretical study of heat extraction from aquifers with uniform regional flow, Jour. Geophy. Res., vol. 80, no. 5, p. 4956.

Gulati, M.S., Lipman, S.C. and Strobel, C.J., 1078, Tritium tracer tests at The Geysers, Trans. Geothermal Resources Council, vol, 2, pp. 237-230.

Harper, R.T. and Jordan, O.T., 1985, Geochemical changes in response to production and reinjection for Palinpinon-I geothermal field, Negros Oriental, Philippines, Proc. 7th New Zealand Geothermal Workshop, Auckland, New Zealand, pp. 30-44.

Hayashi, M., Mimura, T. and Yamasaki, T., 1078, Geological setting of reinjection wells in the Otake and the Hatchobaru geothermal field, Japan, Transactions, Geothermal Resources Council, vol. 2, pp. 263-266.

Henley, R.W., Truesdell, A.H. and Barton, P.B., 1084, Fluid-mineral equilibrium in hydrothermal systems, in Reviews in Economic Geology, by Society of Economic Geologists, Chelsea, Michigan, 350 pp.

Hoang, V.T., James, E.D. and Epperson, J.I., 1987, Heber geothermal field: Reservoir and production characteristics, paper SPE-16330, presented at SPE California Regional Meeting, April 8-10, 1087.

Horne, R., 1982, Geothermal reinjection experience in Japan, Jour. Petr. Tech., vol. 34, no. 3, pp. 495-503.

Horne, R., 1985, Reservoir engineering aspects of reinjection, Geothermics, vol. 14, no. $2 / 3$, pp. $440-457$.

Hosea, H. and Okandan, E., 1986, Reinjection model studies in fractured and homogeneous geothermal systems, Proc. 11th Workshop on Geothermal Reservoir Engineering, Stanford University, Stanford, California, SGP-TR-93, pp. 85-91.

Inoue, $K$. and Shimada, $K, 1085$, Reinjection experiences in the Otake and Hatchbaru geothermal fields, Proc. 7th New Zealand Geothermal Workshop, Auckland, New Zealand, pp. 69-74.

Kasameyer, P.W. and Schroeder, R.C., 1075, Thermal depletion of liquid-dominated geothermal reservoirs with fracture and pure permeability, Proc. 1st Workshop on Geothermal Reservoir Engineering, Stanford University, Stanford, California, pp. 240-257. 
Kindle, C.H., Mercer, B.W., Elmare, R.P., Blair, S.C. and Myers, D.A., 1984, Geothermal injection treatment: Process chemistry, field experience and design options, Pacific Northwest Laboratory report PNL-4767, Richland, Washington, 250 pp.

Lam, S., Hunsbedt, A. and Kruger, P., 1985, Analysis of the Stanford geothermal reservoir model experiments using the LBL reservoir simulator, report SGP-TR85, Stanford University, Stanford, California, 03 pp.

Lauwerier, H.A., 1955, The transport of heat in an oil layer caused by the injection of hot fluid, Applied Scientific Research, Section A, vol. 5, p. 145.

Lippmann, M.J., Tsang, C.F. and Witherspoon, P.A., 1977, Analysis of the response of geothermal reservoirs under injection and production procedures, SPE-6537, presented at the 47th Annual California Regional Meeting of SPE-AIME, Bakersfield, California.

Nuti, S., Calore, C. and Noto, P., 1981, Use of environmental isotopes as natural tracers in a reinjection experiment at Larderello, Proc. 7th Workshop on Geothermal Reservoir Engineering, Stanford University, Stanford, California, pp. 85-89.

Pruess, K. and Bodvarsson, G.S., 1984, Thermal effects of reinjection in geothermal reservoirs with major vertical fractures, Jour. Petr. Tech., vol. 36, no. 10, pp. 1567-1578, LBL-16269.

Pruess, K., Bodvarsson, G.S., Stefansson, V. and Eliasson, E.T., 1984, The Krafla geothermal field, Iceland, 4. History match and prediction of individual well performance, Water Resour. Res., vol. 20, no. 11, pp. 1561-1584.

Pruess, K., Calore, C., Celati, R. and Wu, Y.S., 1987, An analytical solution for heat transfer at a moving boiling front, International Journal of Heat and Mass Transfer, in press.

Sarmiento, F., 1986, Wastewater reinjection at Tongonan geothermal field: Results and implications, Geothermics, vol. 15, no. 3, pp. 295-308.

Schroeder, R.C., O'Sullivan, M.J. and Pruess, K., 1080, Reinjection studies of vapor dominated systems, paper presented at the Italian-American Workshop, Berkeley, California.

Stefansson, V., 1986, Geothermal reservoir management, Draft paper, 45 pp.

Stefansson, V., Gudmundsson, A., Steingrimsson, B., Armannsson, H., Franzon, H., Sigurdsson, O. and Hauksson, T., 1982, Krafla-well KJ-13: Drilling, logging and productivity (in Icelandic), report OS 82046/JHD 07, National Energy Authority, Reykjavik, Iceland, $108 \mathrm{pp}$.

Stefansson, V. and Steingrimsson, B., 1980, Production characteristics of wells tapping two-phase reservoirs at Krafla and Namafjall, Proc. 6th Workshop on Geothermal Reservoir Engineering, Stanford University, SGP-TR-50, pp. 49-59.

Tsang, C.F., Mangold, D.C., Doughty, C. and Lippmann, M.J., 1984, Prediction of reinjection effects in the Cerro Prieto geothermal system, Geothermies, vol. 13, no. 1/2, pp. 141-162.

Vides-Ramos, A., 1085, Ahuachapan, El Salvador, field management, Trans. Geothermal Resources Council, International Volume, pp. 307-404. 